\title{
Porque Usamos Imunoglobulina Anti-D em Excesso no Abortamento Precoce?
}

\author{
Why Do we Waste Anti-D Immunoglobulin in Early Miscarriage? \\ Eduardo Baiochi, Luiz Camano, José Orlando Bordin, Ana Paula Avritscher, \\ Carla Maria de Araújo Andrade, Evelyn Traina
}

\begin{abstract}
RESUMO
Objetivo: avaliação da hemorragia feto-materna (HFM) nas pacientes que receberiam profilaxia da aloimunização $\mathrm{Rh}$ com emprego de imunoglobulina anti-D (300 $\mu \mathrm{g})$, pós-aborto precoce. Método: foram admitidas no estudo pacientes do grupo sanguineo Rh negativo, com parceiro Rh positivo ou ignorado, com quadro de aborto até 12 semanas de gestação internadas para curetagem uterina. Uma amostra de $5 \mathrm{~mL}$ de sangue venoso destas pacientes foi obtida após o procedimento, na qual realizamos o teste qualitativo de roseta para detectar quais casos necessitariam determinação quantitativa do volume de sangue fetal transferido para circulação materna, que foi então apurado pelo teste de Kleihauer-Betke (K-B).

Resultados: das 26 pacientes avaliadas, em uma o teste de roseta foi positivo, e o teste de $K$ $B$ apontou HFM de 1,5 mL.

Conclusões: a dose de imunoglobulina anti-D nos casos de abortamento até a $12^{a}$ semana de gestação deveria ser substancialmente reduzida, parecendo-nos oportuna a disponibilização no mercado nacional de apresentação com $50 \mu \mathrm{g}$, que representaria além da economia, maior racionalidade.
\end{abstract}

PALAVRAS-CHAVE: Hemorragia feto-materna. Imunoglobulina anti-D. Aborto precoce. Rh negativo.

\section{Introdução}

O sangue fetal nos vasos feto-placentários é separado do sangue materno, que circula livre no espaço interviloso, por lâmina de tecido fetal, a qual progressivamente adelgaça-se durante a gestação, de $25 \mu \mathrm{m}$ na décima segunda semana para $2 \mu \mathrm{m}$ no termo da gravidez, quando as trocas materno-fetais são máximas e a superfície da membrana vásculo-sincicial é estimada ${ }^{1}$ em 12 a $15 \mathrm{~m}^{2}$.

A hemorragia feto-materna (HFM) é a transferência de sangue fetal para o compartimento

Universidade Federal de São Paulo - Escola Paulista de Medicina/

Correspondência:

Eduardo Baiochi

Rua Emilio Mallet 465, apto 134 - Tatuapé

03320-000 - São Paulo - SP

Telefone: (11) 6674-9305 Fax: (11) 6674-3916

e-mail:baiochi@ultrarapida.com.br intravascular materno, devido à ruptura na membrana vásculo-sincicial da placenta. A transferência de elementos figurados do sangue fetal constitui a base da etiopatogenia de várias afecções, como se verifica na doença hemolitica perinatal ${ }^{2}$ (DHPN), na plaquetopenia aloimune perinatal ${ }^{3}$, nas reações do tipo enxerto versus hospedeiro e possivelmente na gênese de algumas doenças autoimunes ${ }^{4}$.

Os antígenos eritrocitários de origem exclusivamente paterna existentes no feto, responsáveis pela aloimunização materna, podem pertencer a numerosos sistemas, públicos ou familiares, com poder antigênico variável. Entretanto, em 1941, Levine et al. ${ }^{5}$ já assinalavam que a incompatibilidade Rh entre mãe e feto era responsável por 95\% dos casos da DHPN, indice que ainda se mantém em nosso meio ${ }^{6}$.

O sistema Rh é bastante amplo, mas somente cinco sorotipos estão envolvidos com formas clinicamente significantes da DHPN, a saber: D, C, E, 
c, e, sendo o antígeno $\mathrm{D}$ notoriamente o mais comumente implicado nos casos de aloimunização, devido a sua maior antigenicidade ${ }^{7}$. Diferentemente do sistema $A B O$, no qual anticorpos naturais aparecem após poucos meses do nascimento, no sistema $\mathrm{Rh}$ raramente observa-se a ocorrência destes anticorpos. Sua importância clínica devese à facilidade com que pessoas $\mathrm{Rh}$ negativas podem ser estimuladas a produzir anticorpos anti-Rh, basicamente após transfusão incompativel ou gestação de feto $\mathrm{Rh}$ positivo ${ }^{8}$, uma vez que este antígeno já está bem desenvolvido e expresso nas hemácias do concepto a partir da $6^{\text {a }}$ semana de gestação ${ }^{9}$. Estes fatos tornam os abortamentos, mesmo que precoces, eventos potencialmente sensibilizantes.

Entre nós, o antígeno Rh (D) está presente em torno de $85 \%$ dos indivíduos da raça branca, em 90 a $95 \%$ dos negros e praticamente em $100 \%$ dos amarelos e índios ${ }^{10,11}$. Ocorrências semelhantes foram apontadas na população americana, relatando 9,2\% de uniões com incompatibilidade $\mathrm{Rh}$ entre brancos e 4,5\% entre negros ${ }^{12}$.

Nos anos de 1960 a 1966, grupos de pesquisadores da Inglaterra e dos Estados Unidos (EUA) ${ }^{13}$ realizaram estudos em voluntários, concluindo que era possivel prevenir a aloimunização $R h$ pelo emprego da imunoglobulina $\mathrm{G}$ anti-D que, desde 1968, foi licenciada nos EUA e em 1970 passou a vigorar como programa de saúde pública, para a profilaxia da DHPN.

A dose de $10 \mu \mathrm{g}$ de anti-D para cada mililitro de sangue fetal Rh positivo mostrou-se eficaz em evitar a aloimunização ${ }^{14}$, porém seu exato mecanismo de ação ainda não está totalmente elucidado ${ }^{15}$. O termo HFM excessiva vem sendo habitualmente empregado para designar aqueles eventos nos quais o volume de hemácias fetais transferido para a circulação materna supera a capacidade de neutralização conferida pela dose de anti-D utilizada. Embora a relação dose neutralizante/volume de HFM seja bem estabelecida, a dose mínima de anti$\mathrm{D}$ preconizada varia consideravelmente entre os diversos países.

Embora estejam em andamento estudos com anticorpos monoclonais, produzidos por engenharia genética, toda imunoglobulina anti-D, hoje produzida, ainda é obtida somente a partir de plasma humano, sendo portanto um hemoderivado, informação esta geralmente omitida às pacientes que recebem esta prescrição. Os doadores, em sua maioria, são mulheres pós-menopausadas imunizadas por gestações, bem como homens imunizados voluntariamente, mantidos em estado hiperimune por reaplicações constantes de pequenas doses de hemácias Rh positivas. Esta rotina traz alguns riscos para os doadores, como hepati- tes e imunização contra antígenos eritrocitários não $\mathrm{D}$, além do risco inerente da própria plasmaférese para retirada da imunoglobulina ${ }^{16}$. Acrescente-se a isto que no Brasil todo soro antiD é importado.

Nosso objetivo foi avaliar o volume de sangue fetal transferido para circulação materna nas pacientes pós-abortamento precoce, nas quais se impõe a profilaxia da aloimunização $\mathrm{Rh}$ com imunoglobulina anti-D, a fim de contribuir para a estimativa da dose mais adequada.

\section{Pacientes e Métodos}

Este estudo recebeu parecer favorável dos Comitês de Ética Médica da Universidade Federal de São Paulo/Hospital São Paulo e foi realizado em conjunto pelo Departamento de Obstetrícia, pela Disciplina de Hematologia da UNIFESP-EPM e pelos Hospitais São Paulo e Vila Maria.

Puderam participar do estudo mulheres indicadas para receber profilaxia com anti-D, em face de quadros de aborto precoce (ocorridos até a $12^{\text {a }}$ semana de gestação), que concordaram assinando o Termo de Consentimento Livre e Esclarecido. Durante o período de um ano, entre primeiro de março de 2002 e 28 de fevereiro de 2003, recebemos para avaliação 26 casos que receberiam anti$\mathrm{D}$ diante de quadros de abortamento precoce.

As 26 pacientes da nossa casuística apresentaram média de idade de $25,8( \pm 6,6)$ anos e média de paridade de $1,2( \pm 1,5)$ partos. Das participantes foram obtidos, por acesso periférico, $5 \mathrm{~mL}$ de sangue venoso, acondicionado em frasco com o anticoagulante ácido etilenodiaminotetracético (EDTA), após o completo esvaziamento uterino e antes da administração da imunoglobulina anti-D.

As amostras foram enviadas ao Banco de Sangue do Hospital São Paulo e preservadas sob refrigeração, a $4^{\circ} \mathrm{C}$, até seu processamento. Primeiramente aplicamos o teste qualitativo de roseta. Amostras com resultado do teste de roseta positivo foram submetidas ao teste de eluição ácida, buscando quantificar a HFM.

O teste da roseta foi realizado conforme preconizado pela American Association of Blood Banks ${ }^{8}$ (AABB), da seguinte forma: em um tubo colocamos uma gota do concentrado de glóbulos lavados da amostra sangüinea materna a ser analisada e adicionamos 19 gotas de solução fisiológica a $0,9 \%$, para obtermos uma suspensão a 4\%. A seguir incubamos uma gota desta suspensão, a $37^{\circ} \mathrm{C}$, por 15 minutos, com uma gota de anti-D policlonal $\left(\right.$ ASEM $\left.^{\circledR}\right)$ em tubo de $12 \times 75 \mathrm{~mm}$. Após cinco lavagens com 
solução fisiológica, adicionamos 1 gota de células indicadoras $\mathrm{R}_{2} \mathrm{R}_{2}\left(A S E \mathrm{AM}^{\circledR}\right)$, suspensas previamente em solução de bromelina (Diamed ${ }^{\mathbb{Q}}$ ) a $0,5 \%$, por 15 minutos. Centrifugamos a amostra por 15 segundos a 1000 rotações por minuto, re-suspendemos e então avaliamos sob microscopia pelo menos dez campos aleatórios, no aumento de 10 vezes. A formação de mais que uma roseta a cada três campos foi considerado teste positivo. Destacamos que este teste é $100 \%$ efetivo na detecção de volumes de HFM de $5 \mathrm{~mL}$ ou maiores ${ }^{17}$.

O teste de Kleihauer-Betke foi aplicado segundo estabelecido pela $\mathrm{AABB}^{8}$, da seguinte forma: preparamos esfregaço em lâmina com uma gota de sangue da amostra a ser analisada diluída com uma gota de solução salina. Após secagem ao ar, aplicamos solução fixadora (álcool etílico a $80 \%$ ), por 5 minutos, seguida de lavagem com água destilada. Imergimos então a lâmina em tampão de McIlvaine (solução ácida de citrato tamponada para um $\mathrm{pH}$ de $3,2)$, em temperatura de $37^{\circ} \mathrm{C}$, por 5 minutos. Lavamos novamente a lâmina em água destilada Aplicamos à lâmina a coloração eritrosina $\mathrm{B}$ a $0,5 \%$, por 5 minutos, e lavamos com água destilada, seguindo-se aplicação de hematoxilina de Harris filtrada, por 5 minutos, e lavagem em água corrente por 1 minuto. Contam-se 2000 células, sob microscopia, no aumento de 40 vezes, anotando-se o número de células fetais, que foram identificadas pela sua coloração rósea escura, e de células maternas, que aparecem como células "fantasmas", sendo apurada a porcentagem de hemácias fetais. O volume de HFM em mililitros foi dado pelo produto deste percentual obtido por 50. Controles negativo e positivo foram realizados paralelamente, tanto para o teste de roseta como para o teste de eluição ácida.

A idade gestacional foi definida pelo número de semanas contadas a partir da data da última menstruação, confirmada preferencialmente por exame ultra-sonográfico. Todas as pacientes do estudo receberiam a dose mínima disponivel em nosso meio de $300 \mu \mathrm{g}$ de anti-D, que poderia ser complementada naqueles casos em que o volume de HFM, obtido nos testes aplicados, demonstrasse ser necessário. Os resultados obtidos foram comparados descritivamente com a literatura pertinente.

\section{Resultados}

Entre os 26 casos de abortamento avaliados, houve um único caso no qual o teste de roseta foi positivo, sendo apurado no teste quantitativo de K-B um volume de HFM de 1,5 mL. Tratava-se da paciente ALCS, 22 anos, A Rh(D) negativa, Coombs indi- reto negativo, que deu entrada no Hospital Vila Maria apresentando quadro de atraso menstrual de oito semanas, acompanhado de sangramento genital de odor fétido, dor no baixo ventre e febre de $38^{\circ} \mathrm{C}$. No exame de entrada apresentava colo pérvio, com saida de material sugestivo de restos ovulares, e útero doloroso ao toque bimanual, sendo então internada com diagnóstico de abortamento infectado em curso e submetida a antibioticoterapia seguida por curetagem uterina. Esta paciente evoluiu afebril, tendo alta hospitalar no terceiro dia da internação, após ter recebido profilaxia com anti-D.

\section{Discussão}

Indiscutivelmente, a profilaxia da aloimunização Rh(D) com uso da imunoglobulina é exitosa, obtendo redução de até 100 vezes na ocorrência de sensibilização ${ }^{18}$ e de $83 \%$ na mortalidade de recém-nascidos devido a DHPN ${ }^{19}$. Ressalte-se, porém, que seu efeito é dose-dependente ${ }^{14}$.

Temos atualmente duas grandes correntes em relação à profilaxia da aloimunização $\mathrm{Rh}(\mathrm{D})$, a britânica e a americana (Tabela 1). Tanto no esquema americano como no britânico, está prevista a aplicação de minidoses de $50 \mu \mathrm{g}$ de anti-D, sem necessidade de pesquisa da ocorrência de HFM excessiva, nas gestações interrompidas até a $12^{\text {a }}$ semana $a^{7,8,20,21}$.

Tabela 1 - Esquemas de profilaxia com imunoglobulina anti-D.

\begin{tabular}{|c|c|c|}
\hline $\begin{array}{l}\text { Indicações obstétricas } \\
\text { para anti-D }\end{array}$ & $\begin{array}{c}\text { Padrão } \\
\text { americano }^{A}\end{array}$ & $\begin{array}{l}\text { Padrão } \\
\text { britânico }{ }^{B}\end{array}$ \\
\hline $\begin{array}{l}\text { Interrupção da gravidez até } \\
\text { a 12ª semana }\end{array}$ & $50 \mu g^{*}$ & $50 \mu g^{*}$ \\
\hline $\begin{array}{l}\text { Interrupção da gravidez } \\
\text { após a 12ª semana }\end{array}$ & $300 \mu \mathrm{g}$ & $\begin{array}{c}50 \mu g^{*} \text { até a } 20^{a} \\
\text { semana } \\
100 \mu \mathrm{g} \text { após a } 20^{\mathrm{a}} \\
\text { semana }\end{array}$ \\
\hline $\begin{array}{l}\text { Anteparto (rotina na 28a } \\
\text { semana) }\end{array}$ & $300 \mu g^{*}$ & $100 \mu g^{*}$ \\
\hline $\begin{array}{l}\text { Anteparto (rotina na } 34^{a}- \\
\text { semana) }\end{array}$ & - & $+100 \mu g^{*}$ \\
\hline $\begin{array}{l}\text { Amniocentese, manipulação } \\
\text { ou trauma }\end{array}$ & $300 \mu \mathrm{g}$ & igual à interrupção \\
\hline $\begin{array}{l}\text { Cordocentese ou biópsia } \\
\text { vilo-corial }\end{array}$ & $300 \mu \mathrm{g}$ & Igual à interrupção \\
\hline Hemorragia obstétrica & $300 \mu \mathrm{g}$ & $100 \mu \mathrm{g}$ \\
\hline Pós-parto & $300 \mu \mathrm{g}$ & $100 \mu \mathrm{g}$ \\
\hline $\begin{array}{l}\text { Avaliação da hemorragia } \\
\text { feto-materna excessiva }\end{array}$ & Recomendada & Obrigatória \\
\hline
\end{tabular}

*Dispensada de avaliação para hemorragia feto-materna excessiva. A - Hartwell, 19987; AABB, 19998; ACOG, $1999^{21}$.

B - Royal College of Obstetricians and Gynaecologists, $2002^{20}$. 
Em nosso meio, o Ministério da Saúde, por meio de seu Manual Técnico para Gestação de Alto Risco ${ }^{22}$, define normas para prevenção da sensibilização pelo fator $\mathrm{Rh}(\mathrm{D})$ (Tabela 2), porém não faz qualquer menção sobre a dose de imunoglobulina anti-D a ser aplicada nas diversas situações clínicas, em que pese o fato de dispormos somente das apresentações de 250 e 300 $\mu g$ de anti-D.

Tabela 2 - Normas brasileiras para prevenção da sensibilização pelo fator $\operatorname{Rh}(\mathrm{D})$.

a) Evitar amniocentese nas gestantes Rh negativas não sensibilizadas.

b) Administrar imunoglobulina humana anti-D dentro das primeiras 72 horas em:

- mães Rh negativas não sensibilizadas (Coombs indireto negativo) com partos de recém-nascidos Rh positivos e Coombs direto negativo;

- pós-abortamento, gravidez ectópica ou mola;

- pós-amniocentese, cordocentese ou biópsia de vilosidade corial;

- depois de sangramento durante a gestação.

c) Administrar imunoglobulina humana anti-D durante a gestação de mulheres Rh negativas, com Coombs indireto negativo e com marido Rh positivo entre a $28^{\mathrm{a}}$ e a $34^{\mathrm{a}}$ semana.

Ministério da Saúde, 200022.

A literatura assinala a detecção de HFM em até $28 \%$ das pacientes pós-abortamento ${ }^{23}$ e risco de aloimunização em pacientes suscetíveis de 4 a $5 \%$, diante de quadros de abortamentos terapêuticos, e de 1,5 a $2 \%$ nos espontâneos ${ }^{21}$. Em torno de metade das administrações de anti-D são feitas em pacientes com gestações de até 12 semanas ${ }^{24}$, sendo unânime na literatura dispensar da avaliação de HFM excessiva casos de aborto até a $12^{\text {a }}$ semana de gravide $z^{7,8,20,21}$, preconizando-se o emprego de $50 \mu \mathrm{g}$ de anti-D. Esta minidose de imunoglobulina, que neutraliza até $5 \mathrm{~mL}$ de sangue fetal Rh positivo ${ }^{14}$, é suficiente para a reduzida volemia feto-placentária nesta época da gestação $^{24,25}$, época na qual transferências feto-maternas acima de $3 \mathrm{~mL}$ são altamente improváveis ${ }^{24}$, sendo habitualmente menores que $0,5 \mathrm{~mL}^{23}$.

$O$ consumo de anti-D, entre as pacientes deste estudo, diante dos resultados dos testes realizados, aplicando-se os critérios americano ou britânico, seria da ordem de $1.300 \mu \mathrm{g}$, ao passo que na nossa condição atual de disponibilidade, tão somente de doses de $300 \mu \mathrm{g}$, nosso consumo nas mesmas pacientes foi de $7.800 \mu \mathrm{g}$. Chamamos atenção para o fato de que em nosso país estamos empregando, no aborto precoce, dose seis vezes maior que a recomendada ${ }^{7,8,20,21}$.

Toda imunoglobulina hoje utilizada é proveniente de doadores, cada vez mais relutantes em submeter-se a algum desconforto e possiveis efei- tos adversos, exigindo que se evite ao máximo o desperdício. A disponibilização da apresentação de $50 \mu \mathrm{g}$ de anti-D no mercado nacional encontraria pronta indicação em $10 \%$ de todos os abortamentos precoces, que corresponderiam às pacientes $\mathrm{Rh}$ negativas, levando a redução no consumo de imunoglobulina anti-D da ordem de $83 \%$, nesta indicação.

Assim, fica a pergunta: Por que não dispomos da apresentação de $50 \mu \mathrm{g}$ no mercado nacional?

\section{ABSTRACT}

Objective: evaluation of fetomaternal hemorrhage (FMH) in patients who would need $R h$ alloimmunization with anti-D immunoglobulin $(300 \mu \mathrm{g})$ prophylaxis after early miscarriage.

Method: we included in the study $R h(D)$ negative blood group patients with positive or unknown Rh (D) partners, who had had a miscarriage up to 12 weeks of gestation, and had been admitted to hospital for uterine curettage. After this procedure $5 \mathrm{ml}$ of venous blood was collected from the patients and the rosette test was applied to screen which patients would need quantitative determination of fetal blood transferred to the maternal circulation, by the KleihauerBetke test $(K-B)$.

Results: out of 26 patients evaluated the rosette test was positive in one, who showed an FMH of $1.5 \mathrm{ml}$ in the $K-B$ test.

Conclusions: the dose of anti-D immunoglobulin used in cases of miscarriage up to 12 weeks of gestation should be substantially reduced. The availability of preparations of 50 $\mu \mathrm{g}$ is recommended, for a more inexpensive and rational treatment.

KEYWORDS: Fetomaternal hemorrhage. Anti-D immunoglobulin. Early miscarriage.

\section{Referências}

1. Brossard Y, Pons JC, Jrad I, et al. Maternal-fetal hemorrhage: a reappraisal. Vox Sang 1996; 71:103-7.

2. Zipursky A, Pollok J, Neelands P, Chown B, Israels LG. The transplacental passage of foetal red bloodcells and the pathogenesis of Rh immunisation during pregnancy. Lancet 1963; 35:489-93.

3. Kaplan C, Fórestier F, Daffos F, Tchernia G, Walters A. Management of fetal and neonatal alloimmune thrombocytopenia. Transfus Med Rev 1996; 10:233-40.

4. Nelson JL. Non-host cells in the pathogenesis of autoimmune disease: a new paradigm? Ann Rheum Dis 1999; 58:518-20. 
5. Levine P, Burnham L, Katzin EM, Vogel P. The role of isoimmunization in the pathogenesis of erythroblastosis fetalis. Am J Obstet Gynecol 1941; 42:92537.

6. Cabral ACV, Pereira AK, Assreuy SS, Taveira MR. Isoimunização materna e doença hemolítica perinatal. Realidade e perspectivas. J Bras Ginecol 1998; 108:181-5.

7. Hartwell EA. Use of Rh immune globulin: ASCP practice parameter. Am J Clin Pathol 1998; 110:281-92.

8. Vengelen $\mathrm{T}$, editor. Technical manual. $13^{\text {th }}$ ed. Bethesda: American Association of Blood Banks; 1999.

9. Rote NS. Pathophysiology of Rh isoimmunization. Clin Obstet Gynecol 1982; 25:243-53.

10.Novaretti MCZ. Estudo dos grupos sangüíneos em doadores de sangue caucasóides e negróides na cidade de São Paulo [tese]. São Paulo: Univ. de São Paulo; 1995.

11. Moreira Junior G, Bordin JO, Kuroda A, Kerbauy J. Red blood cell alloimmunization in sickle cell disease: the influence of racial and antigenic pattern differences between donors and recipients in Brazil. Am J Hematol 1996; 52:197-200.

12.Berger GS, Keith L. Utilization of Rh prophylaxis. Clin Obstet Gynecol 1982; 25:267-75.

13. Clarke CA, Donohoe WTA, Durkin CM, et al. Prevention of Rh-haemolytic disease: results of the clinical trial. A combined study from Centres in England and Baltimore. Br Med J 1966; 2:907-14.

14.Pollack W, Ascari WQ, Kochesky RJ, O'Connor RR, Ho TY, Tripodi D. Studies on Rh prophylaxis. 1. Relationship between doses of anti-Rh and size of antigenic stimulus. Transfusion 1971; 11:333-9.

15. Pollack W. Recent understanding for the mechanism by which passively administered Rh antibody suppresses the immune response to $\mathrm{Rh}$ antigen in unimmunized Rh-negative women. Clin Obstet Gynecol 1982; 25:255-65.
16. Krochenour NK, Beeson JH. The use of Rh immune globulin. Clin Obstet Gynecol 1982; 25:283-91.

17. Taswell HF, Reisner RK. Prevention of Rho hemolityc disease of the newborn: the rosette method - a rapid, sensitive screening test. Mayo Clin Proc 1983; 58:342-3.

18.Urbaniak SJ. The scientific basis of antenatal prophylaxis. Br J Obstet Gynaecol 1998; 105 (Suppl 18):11-8.

19.Joseph KS, Kramer MS. The decline in Rh hemolytic disease: should $\mathrm{Rh}$ prophylaxis get all the credit? Am J Public Health 1998; 88:209-15.

20.Royal College of Obstetricians and Gynaecologists. Use of anti-D immunoglobulin for Rh-prophylaxis [online]; 2002 [cited 2003 Sep 3]. Available from: URL: http://www.rcog.org.uk/guidelines/antid.html

21.ACOG practice bulletin. Prevention of Rh D alloimmunization. Number 4, May 1999 (replaces educational bulletin Number 147, October 1990). Clinical management guidelines for obstetriciangynecologists. American College of Obstetrics and Gynecology. Int J Gynaecol Obstet 1999; 66:63-70.

22. Ministério da Saúde. Manual técnico: gestação de alto risco. 3a ed. Brasília: Secretaria de Politicas/ Área Técnica da Saúde da Mulher; 2000.

23.Lakoff KM, Klein J, Bolognese RJ, Corson SL. Transplacental hemorrhage during voluntary interruption of pregnancy. J Reprod Med 1971; 6:260-1.

24.De Crespigny L, Davison G. Anti-D administration in early pregnancy - time for a new protocol. Aust $N$ Z J Obstet Gynaecol 1995; 35:385-7.

25.Morris JA, Hustead RF, Robinson RG, Haswell GL. Measurement of fetoplacental blood volume in the human previable fetus. Am J Obstet Gynecol 1974; 118:927-34. 